Dirac, not only has there been a unification in electromagnetism and optics, but these have also been unified with mechanics. The evolution of physics has therefore followed, to a considerable extent, the pathway marked out by Faraday and Maxwell.

\section{Riboflavin Deficiency in Fowls}

DEFrCIENCY of riboflavin (vitamin $\mathrm{B}_{2}$ ) in chick rations leads to poor growth and may give rise to 'curled toe paralysis'. Where skim milk is available, this trouble is unlikely to occur; but under war-time conditions rearers are forced to depend chiefly on mashes. Official regulations have ensured that all rearing mixtures contain adequate riboflavin; but owing to the fact that essential ingredients such as dried skim milk and dried yeast are in short supply, the possibility of using an alternative source of the vitamin has been investigated by the Chemical Division of the. Agricultural Research Institute of Northern Ireland. The results are published in its sixteenth Annual Report, 1942-43. Chicks were reared from hatching to fourtoen days on a basal ration adequate in protein, minerals, and vitamins $A$ and $D$ but deficient in riboflavin.. They were then divided into groups and supplied with various levels of either dried skim milk or dried liver in addition to their basal ration, one group continuing on the basal ration alone. 5 per cent dried liver was slightly more effective than 10 per cent dried skim milk for growth, and no cases of 'curled toe paralysis' occurred in either group. So little as 1 per cent dried liver improved growth but was insufficient to prevent the leg weakness. A further test fully confirmed these results and also showed that 10 per cent dried lung was as good as 5 per cent dried liver, so that both meals may prove a valuable new source of riboflavin-rich protein supplement for chick-rearing rations. A small stock of these meals has been produced, and work on the subject is being continued.

\section{Literature of Rheology}

In the August issue of the Rheology Bulletin, published by the Society of Rheology under the auspices of the American Institute of Physics, a new feature, "Rheology Reviews", is started with a survey by Dr. R. Dow of "Some Rheological Properties of Matter under High Hydrostatic Pressure". It is intended that the new series shall furnish a perspective of a wide field of knowledge, and that each survey shall be prepared by an expert in the field. In the same number more than twenty pages of abstracts are given. The journal is published quarterly from 175 Fifth Avenue, New York, N.Y., and was founded to help workers in the fields of elasticity, viscosity, plasticity and the like, to a better understanding of their common problems. It was created as a medium for the exchange of information as to theories and methods relating to the rheological properties of matter. The issue for November 1942 contains details of the contents of the Journal of Rheology published by the Society during 1929-33. In 1933 the new journal Physics, now called the Journal of Applied Physics, began to publish the rheological material. Incidentally, the Bulletin illustrates a cheaper method of publication of journals with a small circulation : the matter is prepared on a typewriter with graphs and the mathematical parts added by hand. The copies are then printed by the ase of photo-lithography.

\section{Electrolytic Production of Hydrogen and Oxygen}

"The Production of Hydrogen and Oxygen by the Electrolysis of Water" is the subject of a paper (J. Inst. Elec. Eng., 90, Pt. 1, No. 35 ; Nov. 1943) by Mr. C. E. Bowen, which, reviews the principles and practice of the electrolysis of water and discusses its interest to the electrical engineer. Following the chemical expression of the process, the various factors influencing the yields and power requirements are considered. In the theoretical treatment, the application of Faraday's law is discussed, together with the question of current efficiency. The factors controlling the cell voltage, such as minimum-decomposition voltage, over-voltage, current density and resistance of electrolytes are studied, data being supplied as a guide to the general design requirements of this type of equipment. Methods and materials of construction are also discussed, with some notes on the handling of the gases. The paper describes some modern types of apparatus, and the performance of the equipment is illustrated. The demand for the two gases is discussed and some of their uses are defined. Finally, the author suggests, on the basis of some of the figures included, that the large amounts of power concerned should be of the greatest interest to electrical engineers.

\section{Anti-malaria Campaign in Panama}

A RECENT paper (Bol. Of. San. Panamericana, 22, 502 ; 1943) published by the Malaria Section of the Ministry of Public Health and Public Works of Panama contains an account of the following means adopted against malaria in Panama. More than 300 Anopheles breeding places in the towns of the interior are regularly kept under control by weekly inspection and identification of the larvæ. Eight. species of Anopheles have been identified, namely, A. albimanus, argyritarsis, pseudopunctipennis, apicimacula, albitarsis, strodei and neomaculipalpus. The methods most favoured include the use of oil and Paris green. Paris green, which destroys only the larvæ, is preferred owing to the economy in use and facility of transportation. An approximate idea of the incidence of malaria in the different regions can be obtained from the incidence of malaria mosquitoes and the splenic enlargement and parasitic determination in school children. Rainfall records in infested regions are also of help. Sanitary education by lectures, cinemas, meetings, etc., is slowly progressing.

\section{Treatment of Peripheral Nerve Injuries}

The British Medical Bulletin is published monthly by the British Council for distribution abroad. Each number contains, in addition to valuable summaries of British research papers of medical interest, a special summary of recent work in some field of inquiry, which is written by an authority on that subject. Prof. H. J. Seddon, in an issue devoted to peripheral nerves, writes upon peripheral nerve injuries (Brit. Med. Bull., 1, No. $7 ;$ 1943). Clinical problems presented by nerve injuries have not, he says, received great attention except during times of war, when injuries of peripheral nerves are commoner than they are in normal times. The increasing mechanization of our civilization may, however, result in an increase of peripheral nerve injuries even in times of peace. In 1940 the Ministry of Health and the Medical Research Council established, at civilian hospitals in the Emergency Medical Service, 